\title{
Nutrition, atherosclerosis and coronary heart disease
}

\author{
S Renaud, M de Lorgeril
}

INSERM, Unité 63, 22, avenue du Doyen-Lépine, CP 18,69675 BRON cedex, France

\begin{abstract}
Summary - The main health hazard of atherosclerosis is coronary heart disease (CHD). Its relation to nutrition (chiefly saturated fat) was shown through the Seven Countries Study and confirmed by between country comparisons. Nevertheless, cholesterol, the accepted intermediate link in blood, can no longer be used to explain differences between countries. In addition, when previous trials to decrease CHD by diet were efficient, rapid protection was observed (within a year), an effect not attributed to atherosclerosis but to thrombosis, which is responsible for myocardial infarction. Thrombogenesis is directly increased by saturated fat, but decreased only by n-3 fatty acids and alcohol through decreasing platelet reactivity. A Mediterranean diet with more cereals, vegetables, fruit, less saturated fats and more $n-3$ fatty acids has recently been shown to afford a rapid and exceptional protection from recurrences and death in coronary patients. The relationship between nutrition and $\mathrm{CHD}$ is thus as close as suggested, but more complex, because of additional nutrients, such as alcohol and natural antioxidants, and an appropriate balance between fatty acids.
\end{abstract}

\section{atherosclerosis / thrombosis / dietary habits / saturated fat / polyunsaturated fatty acids}

Résumé - Nutrition, athérosclérose et maladie coronarienne. La principale complication de l'athérosclérose est la maladie des coronaires. Sa relation avec la nutrition, principalement la consommation de graisses riches en acides gras saturés, a été montrée dans létude dite des Sept-Pays et confirmée par les études de comparaison entre pays. Néammoins, le cholestérol sérique, considéré comme le lien intermédiaire entre les acides gras saturés de l'alimentation et les lésions d'athérosclérose, n'explique plus les différences observées entre pays ou régions. De plus, les essais antérieurs de modification du régime pour abaisser la maladie coronarienne, lorsqu'ils ont été efficaces, ont protégé rapidement (en moins d'un an) un effet que l'on ne peut attribuer à une protection contre l'athérosclérose, mais plutôt contre la thrombose, responsable de l'infarctus du myocarde. La thrombogenèse est directement augmentée par la consommation de graisses saturées et abaissée par celle des acides gras polyinsaturés en n-3 et de l'alcool, par diminution de la réactivité plaquettaire. Nous venons de montrer qu'un régime de type méditérranéen avec davantage de céréales, légumes, fruits, moins d'acides gras saturés, davantage d'acides gras n-3, protégeait d'une façon rapide (2 à 3 mois) et exceptionnelle contre les récidives et le décès, chez des patients coronariens. En conclusion, la relation entre nutrition et maladie coronarienne est aussi étroite que le suggèrent les études d'observation, mais elle est plus complexe que prévu, impliquant en particulier l'alcool, les antioxydants naturels et un équilibre des différents acides gras.

athérosclérose / thrombose / habitudes alimentaires / acides gras saturés / polyinsaturés 


\section{INTRODUCTION}

Atherosclerosis is associated with, or accountable, for chronic events such as stable angina pectoris, intermittent claudication, and acute events such as stroke and myocardial infarction. In industrialized countries it is responsible for $30-60 \%$ of total mortality, ie the main cause of death, mostly through coronary artery occlusions or coronary heart disease (CHD).

A number of risk factors have been discovered to be related to these events, such as smoking, hypertension, diabetes and others (The Pooling Project, 1978; Ducimètiere et al, 1980), but none of these seem to be as important as the nutritional factors because in principle they can easily lead to prevention by dietary changes. The additional interest of the nutritional factors is that in the absence of their noxious effects, especially saturated fats, the other risk factors such as smoking, hypertension or even high cholesterol, do not predispose much(Mediterranean countries) or at all (Japan) (Keys, 1970; Renaud and de Lorgeril, 1993) to CHD.

\section{SATURATED FATS AND CHD}

In the Seven Countries Study after 5, 10 or 15 years of follow up (Keys, 1970; Keys et al, 1984), the only nutritional factor closely related to the incidence or the mortality from $\mathrm{CHD}$ was the consumption of saturated fat, as shown in figure 1 .

Since a similar association was found between the level of serum cholesterol and the mortality rate from $\mathrm{CHD}$ (fig 2), it was proposed that the main effect of saturated fat to predispose a patient to CHD was an increase in cholesterol levels. Other studies have demonstrated that saturated fat is the chief factor increasing cholesterol (the

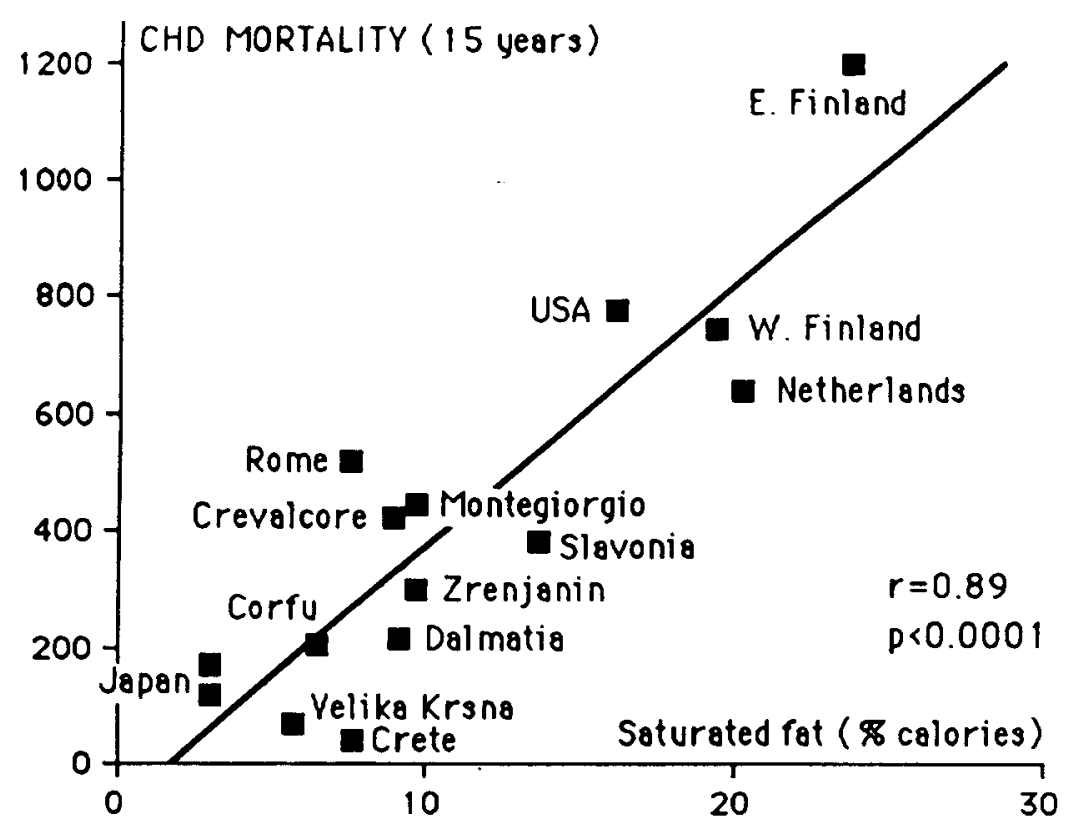

Fig 1. The Seven Countries Study. Relationship between the CHD mortality after 15 years follow-up and the intake of saturated fats at entry (adapted from Keys et al, 1994). 


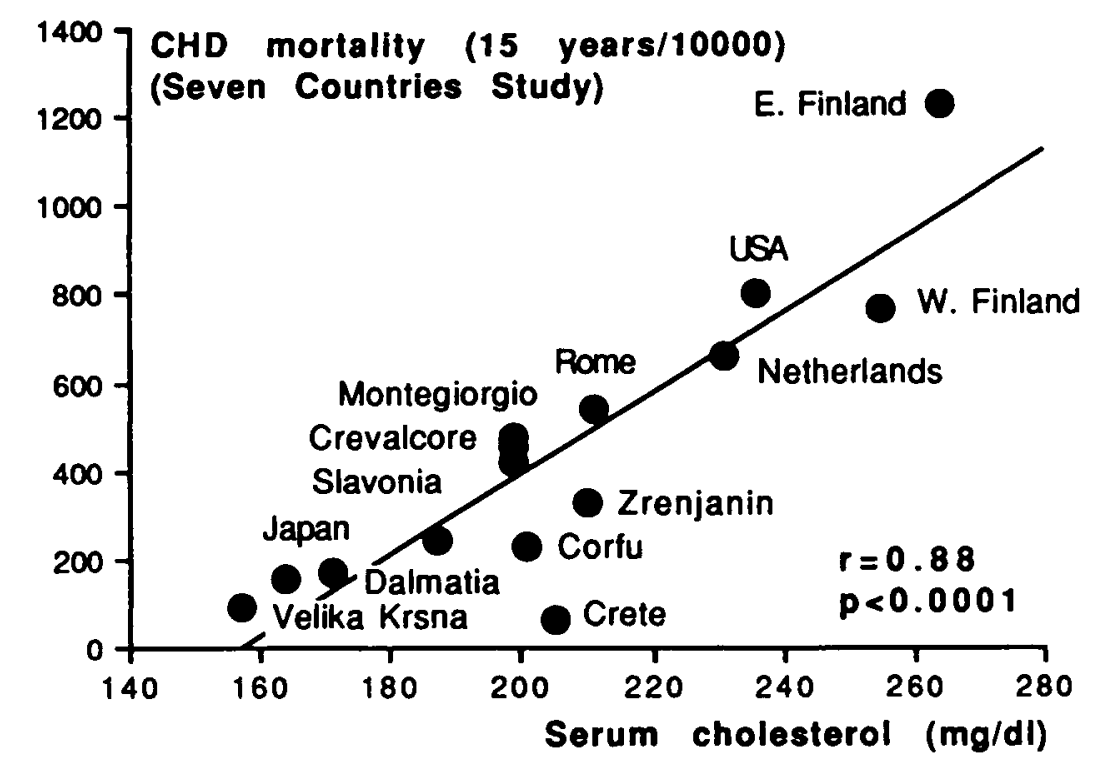

Fig 2. The Seven Countries Study. Relationship between CHD mortality after 15 years and the level of serum cholesterol at entry (adapted from Keys, 1970, and Keys et al, 1984).

equations of Keys and Hegsted) (Hegsted et al, 1993).

The relationship between saturated fats and $\mathrm{CHD}$ has also been observed by simply comparing the mortality rate from $\mathrm{CHD}$ in industrialized countries, as evaluated by the World Health Organization WHO (1989), and the food consumption statistics reported by the Organization for Economic Co-operation and Development (OECD) (1991) or the Food and Agriculture Organization (FAO) balance sheets. Most or all of the saturated fat that is consistently significantly related to the mortality rate from CHD is dairy fat, as shown by Turpeinen (1979). The main reason seems to be, as shown in figure 3, that dairy fat is the most common fat in saturated fatty acids. Nevertheless, when we try to differentiate between the various dairy products, it can be observed that the main foodstuff positively associated with $\mathrm{CHD}$ mortality is the milk fat (fig 4) but not cheese (fig 5). It can be speculated that such data are not the results of real epidemiological studies and consequently are not reliable. Nevertheless, when we try to determine the relationship between milk and cheese consumption and mortality from CHD in the Seven Countries Study, a significant positive association is only found with milk (fig 6) $(r=0.73, p<0.01)$ but not with cheese (fig 7). Thus it seems that cheese could not be as noxious as milk despite the fact that both have a similar general composition in fatty acids, protein and calcium. Further studies are thus required to determine whether the relationships observed in epidemiological studies can be documented by more precise experimental investigation. For the time being these observations can be considered as part of the numerous paradoxes found in the relationships between nutrition and $\mathrm{CHD}$ 
Sat $18: 2 \square$ 18:3 $\square$ Mono

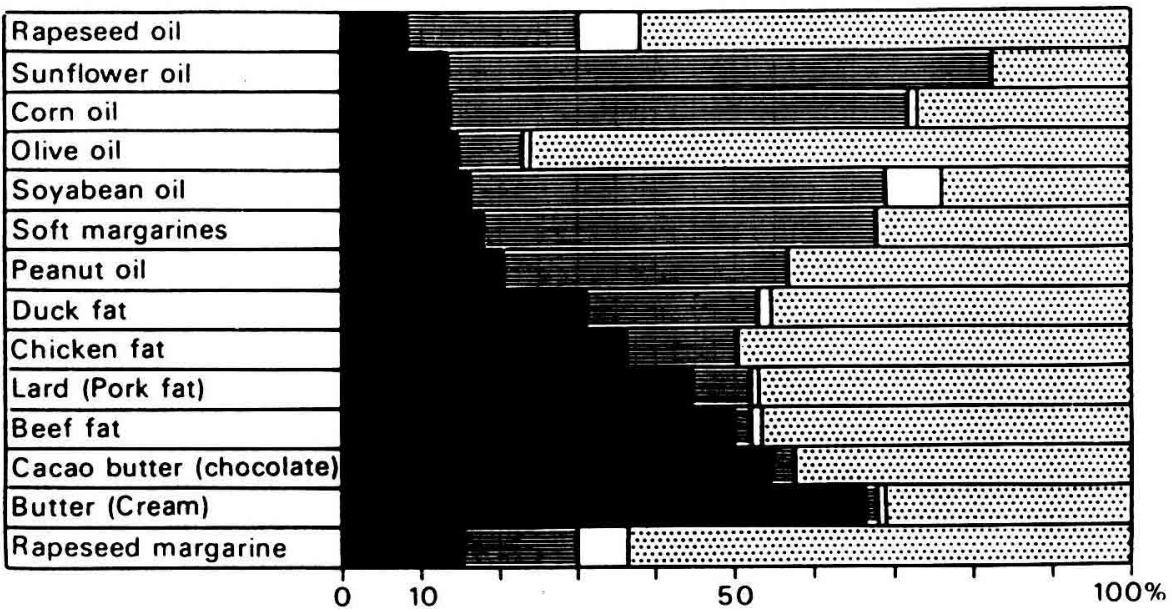

Fig 3. Fatty-acid composition of common fats and oils used in human nutrition. The rapeseed margarine shown above is the experimental margarine, which has been used in our intervention trial. Except for the higher level of $18: 3(n-3)$, its composition is somewhat similar to that of olive oil.

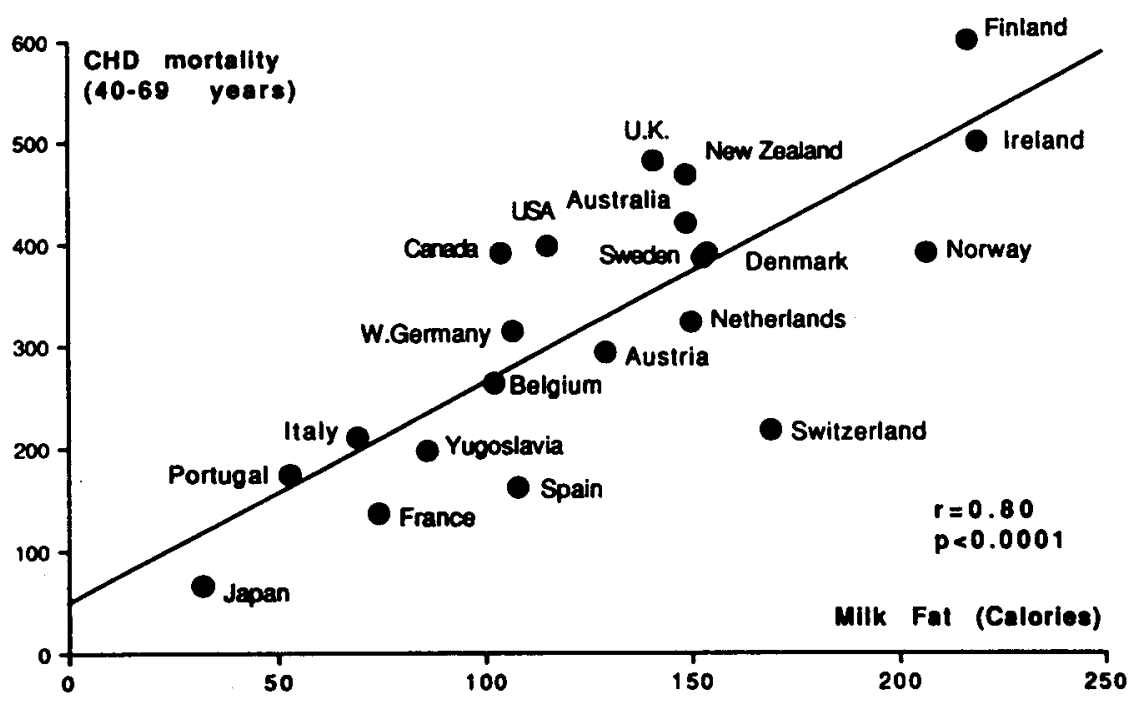

Fig 4. Relationship between the mortality rate from CHD in man (adapted from WHO, 1989) and the intake of milk in the 21 most industrialized countries from the OECD (1991) (mean 1983-1988). 


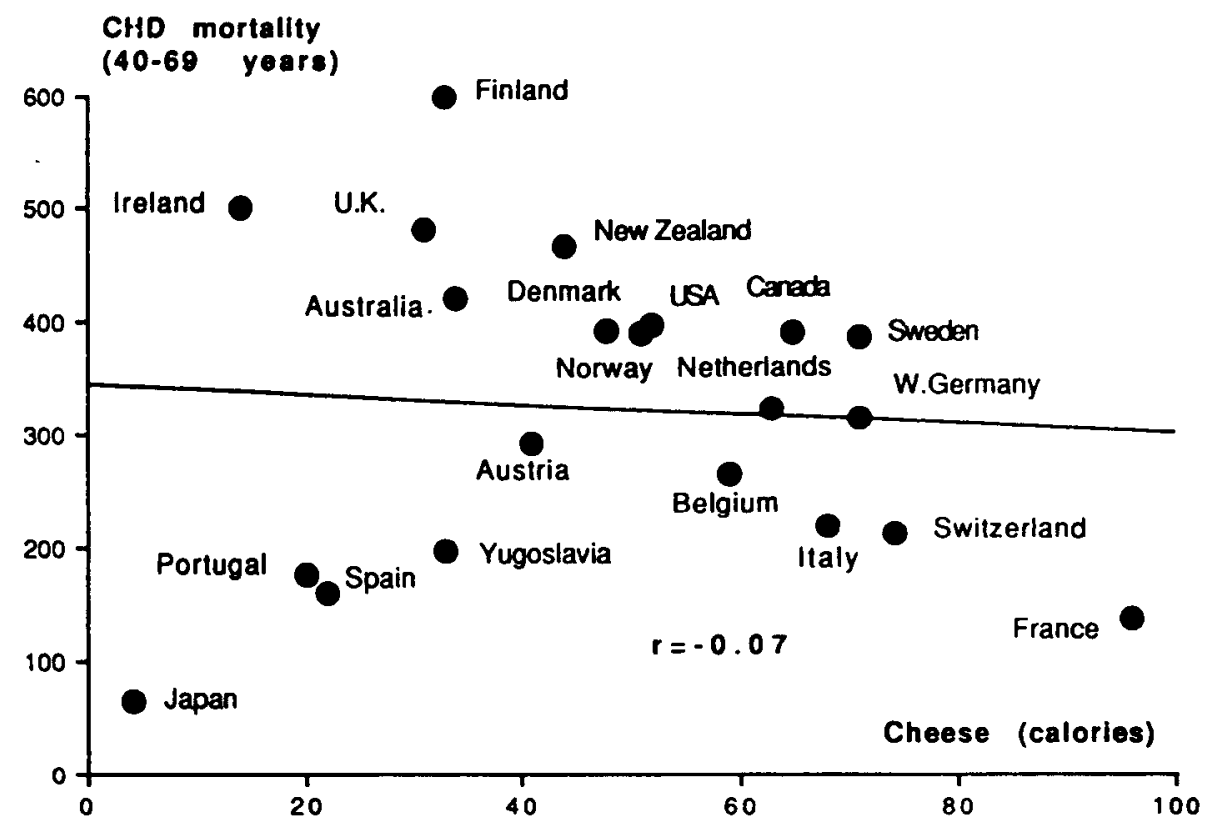

Fig 5. Relationship between the human mortality rate from CHD as in figure 3 and the intake of cheese in the 21 most industrialized countries from the OECD (1991) (mean 1983-1988).

which indicate that so far we have only a superficial view of the mechanisms involved.

Finally, recent data from the Monica project indicate that neither serum cholesterol nor tobacco smoking could explain the differences in the mortality rate from CHD in 37 Monica centers while the plasma levels of natural antioxidants, especially vitamin $E$, can explain at least part of the difference (Gey et al, 1991). This, of course, does not mean that cholesterol has nothing to do with CHD but rather that other factors could be at least as important as serum cholesterol or even lipoproteins for CHD mortality.

\section{CHD PREVENTION TRIALS BY HYPERCHOLESTEROLEMIC DIETS}

The causal relationship between an observation such as CHD and the intake of satu- rated fat or the level of serum cholesterol can only be established by randomized intervention trials. If the trial is performed on patients after a myocardial infarction, it is a secondary prevention. The advantage of this secondary prevention is that in principle it requires a smaller number of subjects to be significant since the main endpoints, myocardial infarction and death, are elevated in the subsequent years $10 \%$ per year a few years ago, now in the range of $6 \%$ per year). There are 3 main trials of this type that have been performed (Morris et al, 1968; Leren, 1970; Woodhill et al, 1978). These were similar in several aspects since they all had 200 patients per group, a 5 year follow up and an experimental group extremely rich in polyunsaturated fat, in such a way the $P / S$ (polyunsaturated/saturated) ratio rose from 1.6 to more than 2.0. As a result serum cholesterol was decreased by approximately $15 \%$. The only trial that 


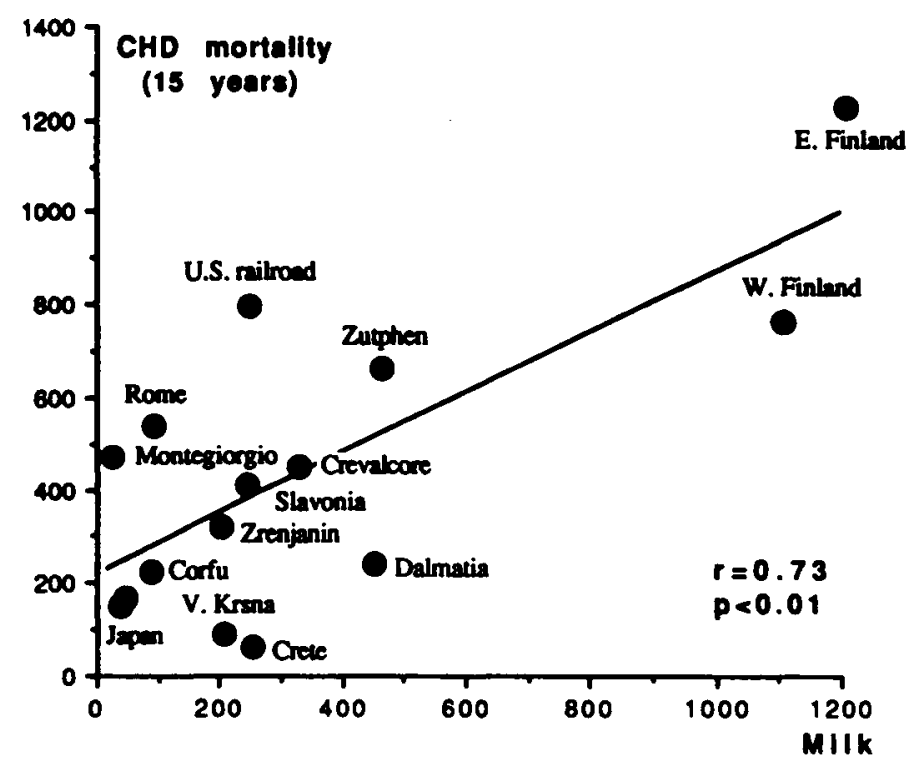

Fig 6. The Seven Countries Study. Relationship between $\mathrm{CHD}$ mortality as in figure 1 and the intake of milk as reported by Kromhout et al (1989).

obtained significant results was the first organized (Leren, 1970) with a decrease of $23 \%$ of coronary events $(p<0.05)$ and a decrease in total mortality of $25 \%$ which was non-significant. In the MRC trial (Morris et al, 1968), the decrease in coronary events was only $15 \%$ (non-significant). In the last trial (Woodhill et al, 1978), the control group had changed their diet spontaneously having a $P / S$ ratio of 0.8 during the trial instead of $0.2-0.3$ as in the other trials. As a result, total death was increased by $50 \%$ in the experimental group suggesting (Renaud and de Lorgeril, 1989) that a P/S ratio of 0.8 was probably much healthier than a P/S ratio of 1.6 or more.

As a conclusion, it has been speculated that after a first myocardial infarction it is too late to expect a beneficial effect of a diet, once the myocardium is already damaged and atherosclerotic lesions extremely severe. It was suggested that it will be only in primary prevention, ie in healthy subjects, that the beneficial effect of a diet could be observed. Several such trials have been performed, with variable success. The most recent, the Minnesota coronary survey on approximately 9000 subjects in mental hospitals (Frantz et al, 1989), used diets that were comparable to those used in the secondary prevention trials mentioned above. In the controls, $18.3 \%$ of the calories came from saturated fat with a P/S ratio of 0.3 . In the experimental group, $9.3 \%$ of the calories came from saturated fats and the $P / S$ ratio was 1.6. Cholesterol was decreased 


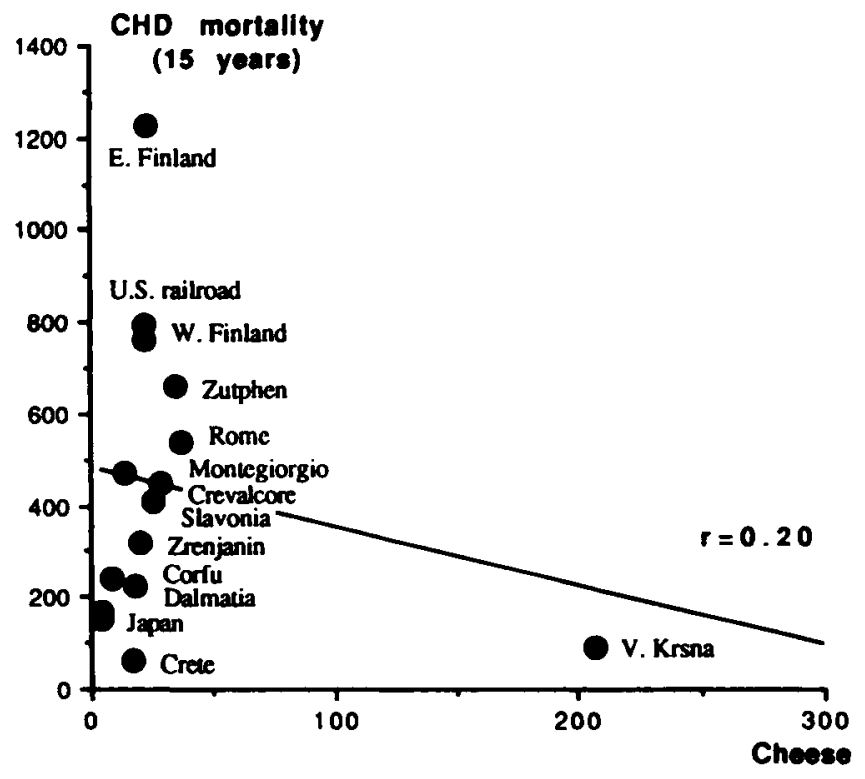

Fig 7. The Seven Countries Study. Relationship between CHD mortality as in figure 1 and the intake of cheese (Kromhout et al, 1989).

by approximately $15 \%$ but after a follow up of 4.5 years (mean), coronary events and total mortality were increased by $8 \%$ in the experimental group. Despite this total failure, we do not conclude that nutrition has nothing to do with CHD but rather that the non-natural diets proposed, even through they are efficient at decreasing cholesterol, had other noxious effects, especially on the blood platelets (Renaud and de Lorgeril, 1989; Renaud 1990). An elevated level of linoleic acid has been also demonstrated to increase peroxidation of LDL (low density lipoproteins), apparently the only truly atherogenic LDL (Abbey et al, 1993; Reaven et al, 1993) related to the level of coronary artery disease (Hodgson et al, 1993).

\section{DIETARY PREVENTION TRIALS AND THROMBOGENESIS}

Myocardial infarction is caused by coronary thrombosis. Platelet reactivity plays an essential role since a drug such as aspirin, that does not decrease cholesterol but markedly lowers platelet reactivity, reduces coronary events by approximately $50 \%$ (Fuster et al, 1989). In addition to their effect on atherosclerosis, saturated fats increase platelet reactivity directly (Renaud et al, 1986). In contrast to cholesterol, linoleic acid increases platelet reactivity while we found that $n-3$ fatty acids (mostly 18:3 (n-3)) decrease it efficiently. Thus if a diet is successful in preventing CHD rapidly (within a 
year), it could act on thrombogenesis, while the effect through cholesterol and atherosclerosis per se could be expected to require 3-4 years as in trials with hypolipidemic drugs (Lipid Research Clinics, 1984). As a matter of fact, the only diet intervention that has been really successful (Hjermann et al, 1981) had a P/S ratio of just 0.7 (Renaud and de Lorgeril, 1989), lowered cholesterol by only $10 \%$ but reduced coronary events and death by a similar $50 \%$ after 1 or 7 years.

\section{THE MEDITERRANEAN DIET AND PREVENTION OF CHD}

The Mediterranean diet is known to be associated with a low mortality rate from $\mathrm{CHD}$ from all causes, especially the Crete diet (Keys, 1970; Keys et al, 1984). After 10 years follow-up in the Seven Countries Study, the mortality from CHD in Crete was $9 / 10000$, while it was $420 / 10000$ in Zutphen (The Netherlands) and 574/10 000 in the USA. Total mortality was $514 / 10000$ in Crete but 1 153/10 000 in the USA. Thus, instead of innovating further by giving patients diets that are not extensively used by any population in the world (ei, the high linoleic acid diet), in 1988 we began a secondary prevention trial on 600 patients after a first myocardial infarction. In this trial, we tried to duplicate the Crete diet in the experimental group compared to a control group receiving the diet prescribed by cardiologists (prudent high polyunsaturated diet). The experimental diet comprised more cereals, vegetables and fruit, less meat and more fish. Butter and cream were replaced by a rapeseed-oil-based margarine designed for this study, with a fatty-acid composition similar to that of olive oil (fig 3 ). Olive and rapeseed oil were recommended for salads and other preparations. After a mean follow-up of 27 months, there was, in the experimental group (de Lorgeril et al, 1993; de Lorgeril et al, 1994), a striking highly significant reduction of all cardiovascular events as well as cardiac and total death. The most surprising results were that the protective effect was already obvious after 2-3 months of diet feeding and that serum lipids (cholesterol, LDL, HDL) were identical in the 2 groups.

In conclusion, as emphasized elsewhere (Renaud and de Lorgenil, 1994), the Mediterranean-type diet, even when adapted to a Western population, protects from CHD much more efficiently that the usually prescribed prudent diet, enriched only in linoleic acid. The factors that may play a role in the protection observed could be: a low intake of saturated fats $(8 \%$ of calories as in Crete); a high level of oleic acid; an adequate ratio (1/5) of $18: 3$ $(n-3) / 18: 2(n-6)$; an increased level of natural antioxidants (vitamin C, polyphenols, partly from red wine) sparing the level of vitamin E; and a moderate intake of meat and wine (Renaud and de Lorgeril, 1994).

Thus, nutrition still seems to be the main environmental factor related to $\mathrm{CHD}$, but in a much more complex way than formerly suspected.

\section{REFERENCES}

Abbey M, Belling BG, Noakes M, Hirata F, Nestel PJ (1993) Oxidation of low-density lipoproteins: intrainvidual variability and the effect of dietary linoleate supplementation. Am J Clin Nutr 57, 391-398

De Lorgeril M, Salen P, Martin JL, Mamelle N, Renaud $S$ (1993) French Mediterranean diet is highly protective against recurrent coronary events. Eur Heart $J 14$ Suppl 19

De Lorgeril M, Renaud S, Mamelle N et al (1994) Mediterranean alpha-linolenic acid-rich diet in secondary prevention of coronary heart disease. Lancet 343, 1454-1459

Ducimetière $P$, Richard J, Cambien F, Claude J (1980) Coronary heart disease in middle-aged Frenchmen. Incidence by risk factor level in the Paris Prospective Study: Comparison with the Seven Countries Study and the Pooling Project. Lancet 2, 1346-1350 
Frantz ID Jr, Dawson EA, Ashom PL et al (1989) Test of effects of lipid lowering by diet on cardiovascular risk. The Minnesota coronary survey. Arteriosclerosis 9, 129-135

Fuster V, Cohen M, Halpern J (1989) Aspirin in the prevention of coronary disease. N Engl J Med 321, 183185

Gey KF, Puska P, Jorda P, Moser UK (1991) Inverse correlation between plasma vitamin $E$ and mortality from ischemic heart disease in cross-cultural epidemiology. Am J Clin Nutr 53, 3265-3345

Hegsted DM, Ausman LM, Johnson JA et al (1993) Dietary fats and serum lipids: an evaluation of the experimental data. Am J Clin Nutr 57, 875-883

Hjermann I, Byre KV, Holme I, Leren P (1981) Effect of diet and smoking intervention on the incidence of coronary heart disease. Report from the Olso study group of a randomised trial in healthy men. Lancet 2 , 1303-10

Hodgson MJ, Wahlquist ML, Boxall JA, Balazs ND (1993) Can linoleic acid contribute to coronary artery disease. Am J Clin Nutr 58, 228-234

Keys A (1970) Coronary Heart Disease in Seven Countries. Circulation 41 (suppl 1)

Keys A, Menotti A, Aravanis C et al (1984) The Seven Countries Study: 2289 deaths in 15 years. J Prevent Med 13, 141-154

Kromhout D, Keys A, Aravanis C et al (1989) Food consumption patterns in the 1960's in Seven Countries. Am J Clin Nutr 49, 888-894

Leren $\mathrm{P}$ (1970) The Oslo diet-heart study. Eleven year report. Circulation 42, 935-942

Lipid Research Clinics Program (1984) The Lipid Research Clinics Coronary Primary Prevention Trial Results. JAMA 251-264

Morris JN, Ball KP, Antonis et al (1968) Controlled trial of soya-bean oil in myocardial infarction. Lancet 2 , 694-700
Organization for Economic Co-operation and Development (OECD) Paris (1991) Food consumption statistics

Reaven P, Parthasarathy S, Grasse BJ, Miller F, Steinberg D, Witztum JL (1993) Effects of oleate-rich and linoleate-rich diets on the susceptibility of low density lipoprotein to oxidative modification in middly hypercholesterolemic subjects. J Clin Invest 91,688-676

Renaud S (1990) Linoleic acid, platelet aggregation and myocardial infarction. Atherosclerosis 80, 255-256

Renaud S, de Lorgeril M (1989) Dietary lipids and their relation to ischaemic heart disease: from epidemiology to prevention. J Inter Med 225 (suppl 1), 39-46

Renaud S, de Lorgeril M (1993) The French paradox: dietary factors and cigarette smoking-related health risks. In: Tobacco Smoking and Nutrition. Ann NY Acad Sci 686, 299-309

Renaud S, de Lorgeril M (1995) The Mediterranean diet to prevent coronary heart disease. Am J Clin Nutr (in press)

Renaud S, Morazain R, Godsey F et al (1986) Nutrients platelet function and composition in nine groups of French and British farmers. Atherosclerosis 60, 3748

The Pooling Project Research Group (1978) Relationship of blood pressure, serum cholesterol smoking habit, relative weight and ECG abnormalities to incidence of major coronary events: Final report of the pooling project. J Chron Dis 31, 201-306

Turpeinen O (1979) Effect of cholesterol-lowering diet on mortality from coronary heart disease and other causes. Circulation 59, 1-8

Woodhill JM, Palmer AJ, Leelarthaepin B, McGlichrist C. Blacket RB (1978) Low fat, low cholesterol diet in secondary prevention of coronary heart disease. Adv Exper Med Biol 209, 317-331

World Health Organization (1989) World Health Statistic Annual. World Health Organization, Geneva 